\title{
NO ROOM AT THE TOP?
}

IT is beginning to seem a long time since the Prime Minister announced, on October 25, that the pattern of scientific research and development in Britain was to be co-ordinated by a Central Advisory Committee on Science and Technology under Sir Solly Zuckerman and responsible to the Cabinet. The delay in assembling the committeemen, and in securing the agreement of the bodies which they will represent, seems to be more than a simple consequence of the fact that the creation of the committee was made public rather sooner than had been planned. It is also likely that some at least of the organizations to be represented on the committee are reluctant to commit themselves to representation until they know what the cost will be.

It is easy enough, of course, to see why some of the ministries should be shy of belonging. The Ministry of Defence, for example, cannot be expected entirely to relish an arrangement whereby an outside body is so powerfully placed that it can determine in important ways the scale and character of programmes in defence research. The same ministry may be especially shy of seeing its chief scientific adviser of a few months ago now emerge as a kind of overlord. Yet the Central Advisory Committee would not make sense if its terms of reference did not extend into defence. A similar though less pointed shyness about the committee probably afflicts the Department of Education and Science and the Ministry of Technology. The fact that the President of the Royal Society, in his anniversary address on November 30, welcomed the prospect of representation on an official committee is so far merely the swallow that does not make a summer.

To guess that powerful interests may be reluctant to cheer about the existence of a co-ordinating committee is not, of course, a reason why such a committee should not exist. On the contrary, if ministries are really afraid that their policies will be nudged in unwelcome directions by advice from the centre, that is on the face of things a proof that co-ordination is necessary. In fact, there is no doubt that the administration of science in Britain deserves to be more closely integrated. For much of the past two years, for example, the Ministry of Technology and the Department of Education and Science have been most distant cousinswhich should not conceal the fact that their relationship is now quickly on the mend. Without question there are likely to be great opportunities for making better use of resources by closer co-ordination between civil and defence research and development, which is one reason for welcoming the absorption of the Ministry of Aviation by the Ministry of Technology. It is easy, for example, to see what profit there might be in systematic attempts to predict the consequences of new defence projects on the supply of skilled manpower in Britain. Yet the question remains of whether a
Central Advisory Committee on the lines described by the Prime Minister is the best instrument for the purpose. That is where doubt now hangs.

The most common suspicion of the new proposals is that they seem, on the face of things at any rate, to represent a return to the old system of advice by oracle. In the past two years committees like the Council for Scientific Policy have broken new ground by carrying out detailed studies of aspects of the administration of science in which important policy decisions were needed. Not merely has this procedure been some guarantee of prudence, but it has also been educative for the scientific community as a whole, not just for the council. Already there has been enough success to show that this is how policy should be made. So far, of course, this record of solid study is meagre and covers only some of the ground, but that is inevitable. It will take time to build up a tradition. In the meantime, it could be thoroughly demoralizing if it were to become accepted that comparatively small issues should be settled with great care and then the grand strategy worked out on the backs of envelopes, on the way from one committee meeting to another. To say all this is not to deny the need of co-ordination, although the lessons of the past few months suggest that if the Central Advisory Committee really does become established, it should work much more openly and much more methodically than the tiny scientific staff at the Cabinet Office will permit. It is also, of course, within the bounds of possibility that the Government will be able to recruit such a band of demi-gods for the committee that all distrust will melt away. In the meantime, however, the Government must expect that the scientific community will keep an open and even sceptical mind.

\section{DECIMAL AND A HALF}

Governments do not usually by their existence evoke sympathy, and the White Paper on the decimal coinage which the British Government has now published (Cmnd. 3164, H.M.S.O., 2s. 6d.) shows why. With fiendish ingenuity the Government has devised proposals for a new monetary system which will at one fell swoop alienate both the diehards for whom the world has not been the same since the golden sovereign disappeared except from costume jewellery, and also those hopefuls who have tried to regard the announcement of decimalization on March 1 this year as a sign that even the Treasury could succumb to rationality. To be sure, the Government has not gone back on its earlier decision, which is something to be grateful for; half decimals are better than none. It is plain from 